\title{
LA ESPACIALIDAD DE LA INTERSECCIÓN: UNA LECTURA POSCOLONIAL DE LA ECONOMÍA POPULAR EN ARGENTINA
}

\section{THE SPATIALITY OF INTERSECTION: A POSTCOLONIAL APPROACH OF POPULAR ECONOMY IN ARGENTINA}

\author{
María Mercedes Palumbo*
}

\section{RESUMEN}

En este artículo se propone identificar las contribuciones de la lectura poscolonial de Partha Chatterjee a la intelección de la economía popular argentina contemporánea como espacialidad de la intersección. Al ser una indagación de corte teórico, las reflexiones esbozadas fueron elaboradas con base en una investigación teórico-empírica en curso que sigue una estrategia metodológica cualitativa. Los resultados indican la productividad analítica de la lectura poscolonial en el estudio de las prácticas cotidianas, los sujetos y las demandas por derechos de la economía popular.

PALABRAS CLAVE: ARGENTINA * ECONOMÍA COLECTIVA * MOVIMIENTO SOCIAL * TEORÍA POLÍTICA

\section{ABSTRACT}

This article aims to identify the contributions of Partha Chatterjee's postcolonial approach to the understanding of contemporaneous popular economy in Argentina as a spatiality of intersection. As a theoretical inquiry, the outlined reflections were elaborated based on a theoretical-empirical research, currently in progress, following a qualitative methodological strategy. The results indicate the analytical productivity of the postcolonial approach in the study of everyday practices, subjects and demands for rights within popular economy.

KEYWORDS: ARGENTINE * COLLECTIVE ECONOMY $*$ POPULAR MOVEMENT $*$ POLITICAL THEORY

\footnotetext{
* Instituto de Investigación en Ciencias de la Educación de la Universidad de Buenos Aires, Argentina.
} mer.palumbo@gmail.com 


\section{INTRODUCCIÓN}

En la vida urbana contemporánea, el trabajo se presenta como un aspecto central en la conformación de las ciudades, sus sujetos $y$ dinámicas. No obstante, resulta necesario abordarlo desde una definición ampliada (Antunes, 2005; De la Garza, 2010) acorde a la heterogeneidad y complejidad de la clase-que-vive-deltrabajo. Para autores como Mezzadra y Morris (2016), se asiste a una multiplicación del trabajo que se expresa en la diversificación interna y en la heterogeneización de los regímenes legales y sociales de su organización, lo que visibiliza la permanencia y la extensión de actividades no asalariadas.

En el caso particular de Argentina, con un fuerte imaginario vinculado a la asalarización, la economía popular ha adquirido un creciente interés de la academia en paralelo al avance de la presencia pública del sector a partir de una serie de movilizaciones sociales $y$ de la sanción de un corpus normativo para su protección. Creada en el año 2011, la Confederación de Trabajadores de la Economía Popular (CTEP) se constituye en un actor que asume un rol organizativo-gremial en la reivindicación de derechos y en la representación colectiva de trabajadores no asalariados.

El supuesto que se sostiene establece que la lectura poscolonial "realista" de Partha Chatterjee $(2008,2011)$, cuyo interés se centra en la política cotidiana de las periferias de las sociedades poscoloniales signadas por la informalidad, aporta interesantes elementos para escudriñar el devenir de la economía popular en la Argentina en clave de espacialidad de la intersección. De allí que el objetivo del presente artículo sea identificar las contribuciones de dicha lectura en tres dimensiones de análisis: el universo de las prácticas cotidianas, la construcción de sus sujetos y la creación de demandas por derechos en el contexto de la economía popular. Tal como establece Castronovo (2018), la economía popular representa un espacio paradigmático para investigar los contornos actuales de lo popular y sus lógicas de funcionamiento.

Este artículo constituye una reflexión teórica elaborada con base en un trabajo de investigación posdoctoral ${ }^{1}$ en curso, en el marco del cual, siguiendo una estrategia general cualitativa, se analizan las dinámicas de construcción de la subjetividad colectiva de los trabajadores de la economía popular nucleados en la CTEP en el Área Metropolitana de Buenos Aires, Argentina. Asimismo, se nutre de un intercambio realizado en la Universidad Nacional Autónoma de México ${ }^{2}$, en el cual se profundizó en torno al abordaje poscolonial de Partha Chatterjee, al tiempo que permitió dimensionar la relevancia del fenómeno de la denominada informalidad en otros países de América Latina.

En aras de organizar la presentación de las reflexiones, se inicia caracterizando brevemente la economía popular en Argentina en términos de su génesis y del proceso de conformación de actores de representación colectiva. A continuación, se pone en diálogo la interpretación de Chatterjee acerca de la informalidad al considerar tres dimensiones de la economía popular: las prácticas cotidianas, los sujetos y la construcción de demandas por derechos. Se prosigue con la recapitulación de los principales argumentos esbozados y la recuperación de los elementos que hacen de la lectura poscolonial,

1 La investigación se sostiene con una beca posdoctoral del Consejo Nacional de Investigaciones Científicas y Técnicas (CONICET) y tiene como lugar de trabajo el Instituto de Investigaciones en Ciencias de la Educación perteneciente a la Facultad de Filosofía y Letras de la Universidad de Buenos Aires (IICE-UBA). Asimismo, se encuadra en el cursado del Programa de Estudios Posdoctorales de la Universidad Nacional de Tres de Febrero.

2 El intercambio posdoctoral fue realizado en el Centro de Investigaciones Interdisciplinarias en Ciencias y Humanidades de la Universidad Nacional Autónoma de México (CEIICH-unam) durante los meses de julio y agosto del año 2018 . Agradezco especialmente a la Dra. Lucía Álvarez Enríquez, investigadora del $\mathrm{CEIICH}$, con quien pude profundizar mis reflexiones en torno al pensamiento de P. Chatterjee para desde allí leer la especificidad del fenómeno de la economía popular en la Argentina. Dicho intercambio fue financiado por un subsidio para la realización de estancias académicas perteneciente al Programa UBAINT DOCENTES 2018 de Becas para la Movilidad Académica Internacional de la Universidad de Buenos Aires. 
una perspectiva fecunda en latitudes distantes del contexto de producción de la obra del autor.

\section{EL FENÓMENO DE LA ECONOMÍA POPULAR EN ARGENTINA}

La historia reciente de la economía popular en la Argentina remite a una serie de procesos que explican la instalación en la escena pública de este sector y de la CTEP, como espacio de representación colectiva. Por un lado, resulta necesario trazar una perspectiva histórico-genealógica que vincule los movimientos y organizaciones de trabajadores desocupados, que pusieron en crisis la legitimidad política del neoliberalismo hacia finales de la década del siglo xx y comienzos del xxI, con las actuales economías populares y sus formas organizativas (Gago y Stzulwark, 2016; Gago, 2014, 2018). Una cuestión no menor -que signa los deslizamientos entre contextos y sujetos colectivos - reside en que, pese al reclamo por trabajo digno, las principales conquistas de los movimientos de trabajadores desocupados se dieron en el campo de las políticas sociales, lo que evidencia actualmente un corrimiento de la acción colectiva hacia la construcción de políticas y derechos laborales bajo el signo de la economía popular.

Por otro lado, los gobiernos kirchneris$\operatorname{tas}^{3}$ que se sucedieron entre los años 2003 y 2015, luego de la crisis económica, política y social de 2001, generaron un cambio en el campo del bienestar y de la protección social (Danani et al., 2018). Una de sus marcas distintivas fue el impulso al cooperativismo (Hopp, 2017) por medio de políticas de promoción de la economía social, proceso denominado como "boom del cooperativismo de trabajo bajo programas" (Arcidiácono y Bermúdez, 2018). Puede explicarse en este impulso al cooperativismo, del cual participaron organizaciones herederas de los movimientos de trabajadores desocupados, un segundo antecedente en la conformación del sector de la economía popular.

3 Se hace referencia al gobierno de Nestor Kirchner (2003-2007) y los dos mandatos de Cristina Fernández de Kirchner (2007-2011, 2011-2015).
Empero, dichas políticas tuvieron una valoración contradictoria de la economía social dado que, aun reconociendo su valor productivo y socio-económico, así como conceptualizando sus actividades y sujetos en términos de trabajo, se les consideraba una "anomalía necesaria" de la dinámica de recomposición social vía el acceso al trabajo formal (Lijterman, 2018). Esta contradicción emergió con más fuerza en torno a la crisis internacional del año 2008 que señaló, de un modo más evidente, los límites que presentaba el modelo económico para asegurar la inclusión laboral, al menos en los términos de la formalidad del trabajo asalariado.

Con base en la hipótesis interpretativa de Tóffoli (2017), el surgimiento de la CTEP como instancia de agremiación de los trabajadores de la economía popular en el año 2011, ya avanzado el ciclo kirchnerista, se explica en la experiencia de una doble desigualdad: a la imposibilidad de acceder a una representación colectiva de sus intereses $y$ demandas como trabajadores, debido a la falta de espacio para los trabajadores de la economía popular en el movimiento obrero organizado ${ }^{4}$, le era concomitante la imposibilidad de erigirse en protagonistas de la recuperación económica promovida por el gobierno. Tal como sostiene la autora, la construcción de la стEP obedece al intento:

...por dar respuesta a un espacio vacante en materia de representación de gran parte de los sectores populares, bajo una modalidad que al tiempo que prioriza su identificación como trabajadores/as,

4 Una excepción a esto fue la experiencia de la Central de Trabajadores de la Argentina (Ста) creada en el año 1992, con rasgos distintivos respecto a la forma sindical tradicional. La стA alentó la incorporación de organizaciones sociales (por ejemplo, trabajadores desocupados) en clave de estrategia de acumulación que quedó condensada en la consigna "la fábrica es el barrio". Lo anterior condicionó la emergencia de demandas vinculadas al trabajo no necesariamente formal-registrado, así como, la presencia de otras formas de movilización y estrategias de construcción territorial. Desde la perspectiva de ciertos estudios (Retamozo y Morris, 2015; Tóffoli, 2017), esta experiencia de la CTA se erige en otro antecedente histórico de la conformación de la CTEP. 
se inscribe en las disputas, lógicas, prácticas y estrategias de uno de los actores colectivos históricamente vinculados a la acción colectiva y la movilización de estos grupos: el sindical (Tóffoli, 2017, p. 62-63).

Resulta importante notar que este sector, con la doble característica de popular e "informal"5, logró aglutinarse en el ámbito de la gremialidad, a partir de la construcción de un dispositivo sindical, antes que en una comunión de tipo ideológica, política, o bien, territorial. De allí, el carácter multiorganizacional de la CTEP que nuclea organizaciones $y$ movimientos populares de diversas matrices político-ideológicas al interior del campo popular, muchos de los cuales reivindican como momento fundacional la ya citada confrontación contra el neoliberalismo de finales de la década del noventa del siglo xx.

Autoras como Abal (2016) han caracterizado a la CTEP como parte del "otro movimiento obrero", surgido por fuera del movimiento obrero sindical, aunque sosteniendo una concepción de unidad que los ubica como parte integrante del movimiento obrero organizado. En consecuencia, esta búsqueda de sindicalización a través de la СTEP estuvo signada, desde sus inicios, por la complejidad implicada en la aceptación de la agremiación de este sector, tanto como en el reconocimiento de su condición de trabajadores y de su voluntad de participación en las instancias de representación colectiva del conjunto.

El caso de la CTEP muestra al trabajo - aún con sus características diferenciadoras respecto al modelo prototípico vinculado a la sociedad salarial/industrial- operando como espacio de identificación y representación. La denominación "trabajador" en la economía popular permitió adoptar una identidad positiva por parte de aquellos que "se habían inventado

5 Los trabajadores que se aglutinan en torno a la CTEP pertenecen a los sectores populares y llevan a cabo trabajos por fuera del ámbito de la formalidad. Empero, no debe seguirse en todos los casos una asociación directa entre sectores populares e informalidad. su propio trabajo" (Grabois, 2017). Si la invención del trabajo actúa como un marcador positivo de una labor con características particulares, la contracara a ser revertida radica en la ruptura del tándem trabajo-derechos vinculada a esta invención; esto es, revertir su condición de trabajadores sin derechos. Como se desarrollará más adelante, la construcción de una demanda por derechos - en clave de derechos del trabajador - atraviesa el discurso $y$ las prácticas de la CTEP tendiendo puentes de igualación con los trabajadores formales sin perder su especificidad. En palabras de Fernández, desde la CTEP:

... se proyectan e imaginan nociones de bienestar donde los sentidos sociales e históricamente construidos en los que el trabajo asalariado (estable y protegido) opera menos como 'paraíso perdido' al que retornar y más como un horizonte desde el que disputar derechos (2016, p. 85).

La alusión a la génesis de la CTEP habilita la comprensión del alcance de la innovación organizacional (Bruno et al., 2017) al encarnar un sujeto colectivo con una identidad bifronte que anuda dos tradiciones. Por un lado, aquella del movimiento sindical que se abocó históricamente a la agremiación y defensa de los trabajadores formales. Por otro lado, la tradición de los movimientos populares donde las referencias a la figura de trabajador $y$ las propias experiencias de trabajo no hallaban centralidad. Esta identidad bifronte condiciona, a su vez, las estrategias de acción de la СТЕP que recupera alternativamente elementos de ambas tradiciones.

Así, se observa la combinación de movilizaciones y acciones directas propias de la impronta de los movimientos sociales, procesos de reconocimiento estatal que llevaron a la obtención de la personería social hacia finales del año $2015^{6}$, necesaria para asentar la representación

6 Si bien, la cTEP buscaba la personería gremial, el 9 de diciembre de 2015, último día de gobierno de Cristina Fernández de Kirchner, se le otorgó la personería social. Tal como señala Abal (2016), la personería social es "una figura débil (en comparación con la personería gremial exigida por la 
colectiva del sector, junto a lógicas de incidencia en la política legislativa y ejecutiva cuyo principal logro ha sido, hasta el momento, la sanción de la Ley de Emergencia Social y de las Organizaciones de la Economía Popular (nro. 27345) ${ }^{7}$ en diciembre de 2016, con vistas a regular la seguridad y las protecciones de los trabajadores de la economía popular.

\section{APORTES DE P. CHATTERJEE PARA PENSAR LA ECONOMÍA POPULAR}

Como se señaló en la Introducción, la lectura poscolonial de Chatterjee, inscripto en los estudios de la subalternidad, aporta interesantes elementos para inteligir el devenir de la economía popular en Argentina descripto sucintamente en el apartado anterior. Para ello, esta investigación se vale de su reconocida obra La nación en tiempo heterogéneo y otros estudios subalternos (2008) tanto como de un libro posterior, menos conocido e inédito en español, titulado Lineages of political society. Studies in postcolonial democracy (2011). El valor de este último radica en el esfuerzo del autor por profundizar algunas de las nociones que ya habían sido esbozadas previamente.

La reelaboración de la perspectiva foucaultiana de la gubernamentalidad para indagar en las prácticas populares poscoloniales, en sus distancias con la normatividad de la democracia liberal moderna y su pretensión de universalidad, se sustenta en una lectura adjetivada — por el propio Chatterjee (2011) _

propia organización) que de todas formas implica para la CTEP un punto de acumulación, a mitad de camino, en el trayecto de pobres a trabajadores pobres" (p.82).

En el marco de esta Ley, se institucionalizó el salario social complementario que garantiza un ingreso para los trabajadores de la economía popular con el objetivo de mejorar sus condiciones de vida y permitir el acceso a la seguridad social. El salario social complementario genera y enmarca debates políticos y académicos respecto a si es un reconocimiento del trabajo en clave de derechos o una asistencia social a la pobreza encubierta. Adicionalmente, reformula la vinculación de las organizaciones $y$ los movimientos del sector con el Estado, así como trastoca la lógica de funcionamiento de los movimientos y sus formas de trabajo. como realista. Se comprende que la cualidad de realista deriva, al menos, de dos elementos. Por un lado, su perspectiva se ubica lejos de la heroicidad y la espectacularidad de la política para centrarse en la mundanidad de la micropolítica cotidiana de las periferias de las metrópolis $y$ de las transacciones informales que la circundan. Por otro lado, y en vinculación con lo anterior, su lectura es realista en tanto situada $y$ descriptiva -en oposición a lo normativo-, siendo sus referentes empíricos las sociedades poscoloniales asiáticas $y$, específicamente, las de la India. Aquí se sostendrá la posibilidad de hacer extensible sus premisas a las latitudes latinoamericanas sin desconocer las marcadas diferencias existentes entre ambos contextos.

Para los fines de este artículo, interesa particularmente recuperar la aproximación del autor a la dimensión de la informalidad que dialoga en su obra con la crítica al Estado-nación moderno, las democracias liberales, el sistema legal occidental y el mismo capitalismo. Al seguir la clave interpretativa de Álvarez (2019), Chatterjee contribuye a identificar la estrategia de expulsión, omisión y exclusión de la cual emergen la informalidad y lo informal en su condición de lo externo, periférico, marginal o excepcional (siempre en relación con una regla asumida como universal). De la identificación de esta estrategia se deriva la visibilización, validación y dignificación postulada por Chatterjee de una serie de sujetos, lógicas, conquistas, institucionalidades y derechos "informales" que no se encauzan a través de las mediaciones institucionales modernas implicadas en los trayectos de ciudadanización $-y$ se agrega de asalarización- clásicos.

A continuación, se abordan las contribuciones de esta lectura poscolonial en la articulación con el caso de la economía popular argentina con base en las dimensiones de análisis explicitadas. Cada una de estas dimensiones se estructura en torno a una tensión entre nociones presentes en la perspectiva de Chatterjee, acorde a la intencionalidad del autor de contraponer el paradigma normativo ( $y$ sus equivalentes: occidental, moderno, liberal) con la sucesión de desviaciones y excepciones a la norma de carácter empírico (Chatterjee, 2011). 
Sin embargo, estas nociones en tensión no deben ser pensadas en términos de mutua exclusión sino de intersección, lo cual abona a la existencia de una serie de grises. Justamente, tal como se sostendrá de aquí en adelante, serán los grises el ámbito de inscripción de la economía popular en su condición de espacialidad de la intersección.

\section{A) EL UNIVERSO DE LAS PRÁCTICAS COTIDIANAS: LO LEGAL, LO ILEGAL Y LO PARA-LEGAL}

Las prácticas cotidianas de los sectores que integran la economía popular han sido, a menudo, significadas por las políticas públicas como por los estudiosos de la temática en términos de informalidad. Desde un discurso anclado en la noción de economía popular ${ }^{8}$, la CTEP discute dicho concepto con base en una serie de elementos: 1) invisibiliza la existencia de estructuras y normas propias que la regulan constituyendo, por el contrario, una estructura adjetivada como compleja (Giraldo, 2017) y barroca (Gago, 2014); 2) la demarcación por oposición con lo formal eclipsa que, pese a su especificidad, se encuentra indefectiblemente articulada con la economía capitalista, aunque desconectada de los mecanismos de integración y protección social de la condición de asalariado, y con las políticas sociales y socio-laborales estatales; 3) la dualidad planteada por la distinción formal e informal impide reconocer la multiplicidad de situaciones laborales que alberga cada conjunto. Más allá de sus diferencias, el punto de encuentro entre economía popular e informalidad radica en situar su especificidad en la trascendencia de la lógica de la ganancia y la vinculación con la reproducción ampliada de la vida.

Aun cuando la lectura de Chatterjee retome la idea de informalidad, se considera que su conceptualización trasciende las críticas que se realizan a dicha noción desde la economía

8 La noción de economía popular es tanto una categoría académica como una "categoría de la práctica” (Fernández, 2015); esto es, una categoría utilizada en la jerga cotidiana de las organizaciones y movimientos del sector $y$, de igual modo, en el discurso científico. popular. En coincidencia con Álvarez (2019), se sostiene que más que una oposición entre formalidad e informalidad, el autor se adentra en un proceso amplio $y$ multidimensional de desbordamiento de los ámbitos institucionales $y$ normativos, $y$ de la esfera del capital en general, que no reenvía únicamente a la vida económica. Este proceso amplio engloba distintos gestos que se evidencian en actividades económicas, al tiempo que comprenden prácticas sociales, formas de politicidad $y$ procesos de gestión de lo social.

Al clásico estar "por fuera de" (lo formal, la regla), se suma el transcurrir "en paralelo a" la dinámica institucional. Ambos gestos - la exterioridad y el paralelismo, tanto como sus corolarios: la ilegalidad y la para-legalidadson parte de la ya aludida crítica al concepto de informalidad, al remitir a una mera distinción en términos de dualidad excluyente, respecto a lo formal, sea este el trabajo asalariado, los derechos legales o las instituciones democráticas. Ahora bien, aun cuando su énfasis se encuentre posiblemente en el paralelismo, es factible hallar en el pensamiento de Chatterjee un tercer gesto que apunta a la "interpenetración con". En esta línea, Gago (2018) interpreta a las economías populares como una "espacialidad de intersección" (p.12) que discurre entre lo formal y lo informal, la subsistencia y la acumulación, lo comunitario y los cálculos de beneficio.

Esta aproximación al universo de las prácticas cotidianas de los trabajadores de la economía popular se distancia de otras que las significan como sinónimo de ilegalidad, con lo que complejiza igualmente aquellas visiones que solo las postulan como experiencias micro-sociales desarrolladas en paralelo a la formalidad-legalidad. Para el autor, la cuestión no se resuelve en la integración de lo exterior y lo paralelo al sistema formal (sea institucional, laboral), tampoco le resta dimensión instituyente a las prácticas populares ni descarta el mundo de las transacciones entre los gobernados y el Estado. Al respecto, el caso de la CTEP demuestra la existencia de una vocación de incidencia estatal en leyes y políticas públicas, al posicionar a sus sujetos como interlocutores en, 
con y frente al Estado, en línea con la idea de intersección.

De igual manera, este sujeto colectivo pretende intervenir en las mediaciones colectivas institucionalizadas de los trabajadores, como es el movimiento obrero organizado, para la incorporación de un sector que, de antemano, no cumpliría con los requisitos de la afiliación sindical clásica. La referencia a "la política de los gobernados" (Chatterjee, 2008) plantea que los gobernados hacen política — se podría decir también que "los informales" trabajan, que los trabajadores no asalariados producen valor $y$ brindan servicios $y$ cuidados necesarios para la sustentación de la vida social—, al no ser simplemente objeto de técnicas que los dirigen pasivamente.

Roy (2009) introduce, en la enunciación de sus premisas sobre la informalidad para las mismas sociedades asiáticas que interpreta Chatterjee, la idea de que el Estado es una entidad que utiliza activamente la informalidad como modo de disciplinamiento, regulación y autoridad, al ser lo informal una característica de las estructuras de poder. De allí que lo formal y lo legal deban entenderse como ficciones volátiles, ambiguas e inciertas que convergen, a menudo, con procesos extra-legales $y$ para-legales.

En clave de complejización, esta autora plantea trascender las equiparaciones entre informalidad y lógicas desde abajo, o inclusive informalidad y pobreza, para reparar en la informalidad desde arriba, propia de las instituciones que se erigen, al decir de Chatterjee, en insignias del paradigma universal de la democracia liberal moderna. Por lo tanto, no solo la penetración de dicho paradigma ha sido parcial en su instalación en las sociedades poscoloniales, sino que incluso los ámbitos y los espacios que sí fueron permeados se rigen por lógicas y pautas distintas a las que se asientan en su base normativa. Si bien, Roy (2009) presenta sus premisas en diálogo crítico con el populismo neoliberal del peruano Hernando de Soto (1987) como con la política subalterna de los teóricos poscoloniales, especialmente apunta a Chatterjee por su excesiva atención a "... la informalidad como una revolución subalterna desde abajo" (Roy, 2009, p. 84) , su perspectiva complementa más que invalida la lectura del autor indio. En la obra de Chatterjee se encuentran sendas referencias a la gestión diferenciada de accesos, pertenencias, membrecías y derechos —en este último caso, bajo la particular diferenciación entre rights y entitlements - que se teje en la vinculación de los gobernados con las autoridades estatales. De allí que el universo de las prácticas cotidianas de estos sectores populares, en las que se inscribe la economía popular en Argentina, transcurra entre la exterioridad, el paralelismo y la interpenetración con las normas e instituciones, estando ellas mismas atravesadas por la informalidad.

B) LOS SUJETOS DE LA ECONOMÍA POPULAR: TRABAJADORES, CIUDADANOS Y POBLACIONES

La definición del sujeto de la economía popular, con su especificidad respecto al trabajador asalariado, resultó un aspecto clave del proceso organizativo del sector en Argentina. Máxime si se repara en las dificultades encontradas para la percepción de sí mismos y de otros en condiciones similares como trabajadores y en los obstáculos para el reconocimiento de la unidad existente entre trabajadores de distintas ramas que componen el heterogéneo universo de la economía popular. Sin lugar a duda, la construcción del sujeto de la economía popular implicó el pasaje de la constitución de los sujetos en términos de beneficiarios de un programa social gubernamental hacia la asunción de sí como trabajadores. Aquí interesa considerar los aportes de la lectura de Chatterjee para analizar la inscripción de la subjetividad colectiva del trabajador de la economía popular en sus vinculaciones con el ciudadano y la población, en su condición de sujetos paradigmáticos de la sociedad civil y política, respectivamente.

En la lógica de los términos duales que, empero, se imbrican, la lectura poscolonial de Chatterjee aporta la distinción conceptual entre sociedad civil y sociedad política. Al decir

$9 \quad$ Traducción del original que versa: “...informality as a subaltern revolution from below". 
de Álvarez (2019), dicha distinción singulariza dos fenómenos políticos protagonizados por sujetos distintos y que operan bajo lógicas divergentes sin que se traduzca en una separación o autonomía entre ambas en las prácticas concretas. En una reelaboración de la teoría liberal, Chatterjee $(2008,2011)$ circunscribe la categoría de sociedad civil a los sujetos que responden cabalmente al ideal universal del ciudadano - a lo nacional homogéneo-, cuyas prácticas y estrategias se orientan en torno a dinámicas de ciudadanización, en las cuales se procesa el reconocimiento de plenos derechos por parte del Estado. Por su parte, la noción de sociedad política visibiliza el ámbito informal de actuación donde accionan vastos grupos sociales ${ }^{10}$, llamados poblaciones con acceso diferencial —o falta de este- a los derechos ciudadanos.

De este modo, la sociedad política traza la apertura hacia transacciones cotidianas e informales con el Estado, de las cuales puede resultar el otorgamiento de beneficios mediado por negociaciones, acuerdos $y$ disputas ${ }^{11}$. Nuevamente, se encuentra aquí un elemento de la lectura realista del autor en tanto decide anclarse en la realidad empírica, que comprende sociedad civil y sociedad política, antes que al ideal normativo circunscripto a su caracterización de la sociedad civil: “... el dominio de la sociedad política, infundido por las movilizaciones populares, actúa como un recordatorio constante de la fundación abstracta de la democracia en la soberanía popular"12 (Chatterjee, 2011, p.147).

$10 \quad$ Cabe aclarar que no debería asumirse linealmente una lectura en clave de clase social para definir a los actores que integran la sociedad civil y la sociedad política. En este sentido, la sociedad política se encuentra constituida por diversos grupos sociales e, incluso, clases.

11 Si bien, el autor es crítico de la ficción que implica la mecánica de la sociedad civil y los ciudadanos, en su incompatibilidad con las condiciones reales de existencia de las sociedades poscoloniales, tampoco idealiza el ámbito de la sociedad política y las poblaciones dado que entiende que allí pueden desplegarse modalidades de organización como el clientelismo y las redes de mafia (Chatterjee, 2011).

12 Traducción del original que versa: “...the domain of political society, infused by popular mobilizations,
Así, las poblaciones -o su sinónimo: los gobernados - se oponen a los ciudadanos en cuanto a sus ámbitos de pertenencia, con lo cual condicionan estrategias, acceso a derechos, formas de interlocución estatal y hasta su significado ético. En el plano de la gubernamentalidad ${ }^{13}$ propia de la sociedad política que opera como saber y tecnología, las poblaciones son definidas mediante la identificación de características comunes empíricamente observables dentro de la heterogeneidad constitutiva de lo social. Parafraseando a Gago (2014), la población resulta una manera menos abstracta de nombrar a los sectores populares de las metrópolis poscoloniales.

Empero, cabe aclarar que este abordaje no descarta al sujeto ciudadano, sino que denuncia la falta de exhaustividad de la categoría. Tampoco se delimita un referente empírico unívoco para la población. Al respecto, resulta interesante la alusión a un "Estado etnográfico" (Chatterjee, 2008, p. 192) que ubica al Estado operando a la manera de un etnógrafo que delimita, clasifica y conforma a los diversos destinatarios-objeto de las excepciones, a quienes interpela de modo fragmentario. En el caso de la economía popular en Argentina, la noción de Estado etnográfico remite a la disputa nominativa entre la referida construcción de la figura de los trabajadores de la economía popular por parte de la СTEP, como nombre de la subjetividad colectiva y las demarcaciones de la etnografía estatal - también presentes en los medios de comunicación masivos - que utiliza alternativamente los apelativos de movimientos sociales, piqueteros y organizaciones sociales.

acts as a constant reminder of democracy's abstract foundation in popular sovereignty".

13 Chatterjee, en su reelaboración del concepto foucaultiano para las sociedades poscoloniales, entiende a la gubernamentalidad como “... el manejo de poblaciones a través de políticas públicas, en sustitución de la representación basada en la soberanía ciudadana" (2008, p.38). En este sentido, la gubernamentalidad indica el campo $y$ las estrategias de una forma especial de hacer política por parte de las agencias gubernamentales que implica a los sectores populares informales y al terreno de la heterogénea vida social mundana. 
De la descripción anterior relativa a la distinción entre sociedad civil y sociedad política $-y$ sus sujetos: los ciudadanos y las poblaciones - se abreva a una serie de equivalencias que permiten reflexionar sobre la inscripción del trabajador de la economía popular en las coordenadas del pensamiento de Chatterjee. Por un lado, es posible establecer una correspondencia entre ciudadano, trabajador asalariado y sociedad civil. Aquí cabe aclarar, en pos de evitar caer en ingenuidades, que el trabajador asalariado se encuentra sometido a condiciones de informalidad en el marco de la creciente precarización y flexibilización laboral. Por otro lado, existe una segunda correspondencia trazable entre población, trabajador de la economía popular y sociedad política.

Estas series de equivalencias colocan dos corolarios que actúan en sentidos opuestos, aunque convergentes, al mostrar sus disyunciones como sus imbricaciones no exentas de paradojas. El primero concierne al creciente reforzamiento del estatuto ciudadano por aquellos que transcurren en el ámbito de la sociedad civil (Leal, 2016). En el campo de las relaciones sociolaborales, este reforzamiento se observa en la reacción conservadora de ciertos trabajadores asalariados sindicalizados ante la gremialidad de los trabajadores de la economía popular, con base en discursos que sostienen que estos llevan los salarios a la baja y que no les importa gozar de menos derechos.

En última instancia, se actualiza la escisión entre trabajadores (formales) y beneficiarios de programas gubernamentales, la cual niega la identidad laboral a los trabajadores de la economía popular. Para utilizar la expresión de Abal (2016), se reedita "... la antinomia imaginaria entre trabajadores que se rompen el lomo y planeros que viven del Estado"14 (p. 81). Un corolario adicional resulta de la apelación realizada por "los informales" a las figuras del

14 Del lenguaje coloquial, la frase "romperse el lomo" - adjudicada en la cita a los trabajadores formales - significa trabajar muchas horas conllevando un esfuerzo excesivo. Por su parte, la referencia a "planero" implica un modo despectivo de interpelar a quienes son beneficiarios de un programa o plan social gubernamental. trabajador asalariado y del ciudadano como base de sustentación para reclamar su acceso a derechos de seguridad social, aun siendo dos categorías que históricamente los excluyeron como sus sujetos en el devenir de sus estrategias de expulsión, omisión y exclusión.

En efecto, la invitación de Chatterjee reside en pensar a los sujetos de la política popular, extensible a los trabajadores de la economía popular en análisis, desde un abordaje que apunte a la desliberalización y la despasivización. Si la ciudadanía es la contraparte mediadora de la política occidental moderna, la población representa la contraparte mundana - y barrial - de la política para grandes sectores de las sociedades poscoloniales.

En esta línea, el trabajador asalariado es al ciudadano lo que el trabajador de la economía popular es a la población. Más que una desviación de la ciudadanía (o de la institución laboral), la lectura realista señala las distancias entre espacios, instituciones, prácticas, derechos y discursos que se trazan entre ciudadanía $y$ población, entre trabajador asalariado y de la economía popular. En cuanto a la despasivización, en un esfuerzo por evitar análisis unidireccionales, el autor postula que los sujetos se agencian en la búsqueda por forzar negociaciones $y$ constituirse en interlocutores válidos de las autoridades gubernamentales como en la mecánica de la propia interlocución.

Los sujetos de la sociedad política se apropian, rechazan y negocian los mecanismos de gubernamentalidad que pretenden objetualizarlos, al potencialmente impulsar transformaciones en las políticas estatales (Gago, 2014). De este modo, intervienen en los modos y en los términos en los que quieren ser gobernados en el marco de las luchas por las conquistas concretas y locales, en la reapropiación que realizan de los recursos estatales obtenidos y hasta en la disputa con los lenguajes gubernamentales de corte etnográfico.

C) LA CREACIÓN DE UNA DEMANDA POR DERECHOS: DERECHOS LEGALES (RIGHTS) Y DERECHOS ADQUIRIDOS (ENTITLEMENTS)

La economía popular se caracteriza por el hecho de que sus actividades se encuentran 
al margen de la ley, al no cumplir con los códigos laborales, tributarios y registros mercantiles propios de las normas vigentes (Giraldo, 2017). Estar fuera de la ley no es equivalente a considerarlas formas de trabajo ilegal. Se debe reparar en la existencia de una pluralidad de órdenes legales que comprenden el desarrollo de una regulación no-estatal en la vida social frente a la inaplicabilidad del derecho legal. En este sentido, resulta de utilidad la diferenciación realizada por Chatterjee (2008; 2011) entre derechos sustentados legalmente (rights) y derechos adquiridos por uso continuo (entitlements) ${ }^{15}$, que se imbrica con los conceptos de sociedad civil y sociedad política, de ciudadanos $y$ poblaciones, presentados en el apartado anterior.

Ambos tipos de derechos difieren en su diverso carácter jurídico, en las formas alternativas desplegadas para su obtención, en sus distintos sujetos destinatarios y en sus disímiles características de extensión y duración. Los rights asumen el estándar jurídico de la sociedad civil, reconocen a los ciudadanos y pretenden un alcance universal, nacional-homogéneo y duradero.

Por su parte, los entitlements no cumplen con el estándar jurídico, surgen como resultado de acuerdos en el marco de la negociación política con las autoridades en la arena

15 La diferenciación entre ambos tipos de derechos es presentada por Chatterjee (2008) a partir del caso de los ocupantes de asentamientos junto a las vías del tren en Calcuta: "Una propuesta interesante para encarar la maraña de situaciones paralegales existente en este ámbito es la distinción entre derechos sustentados legalmente (rigths) y derechos adquiridos por el uso continuo (enlitlements). Los derechos sustentados corresponden a quienes poseen un título de propiedad legal de las tierras $y$ bienes inmuebles susceptibles de ser expropiados por las autoridades. Ellos son, podríamos decir, propiamente ciudadanos a quienes se les debe pagar la compensación estipulada. Actúan en el marco de la ley y son protegidos por ella. Quienes no poseen tales derechos sustentados pueden, no obstante, poseer derechos adquiridos. En este sentido, no les correspondería compensación, pero quizás si asistencia para reconstruir su hogar o para encontrar una nueva fuente de sustento" (pp. 145-146). de la sociedad política, son parciales y heterogéneos al asignarse a poblaciones bien delimitadas en carácter de excepción, se definen por su inestabilidad $y$ fragmentariedad, en tanto poseen una duración "de momento", siempre pasible de nuevos acuerdos. De acuerdo con Álvarez (2019) en línea con Chatterjee (2011), si bien, el reconocimiento hacia los derechos adquiridos se sustenta al nivel de la tolerancia o del aval sobre ciertas prácticas ilegales o paralegales, antes de ser un reconocimiento legal, la conquista de derechos concretos es una de las formas en que los gobernados pueden ganar espacios para condicionar y definir los modos en que quieren ser gobernados.

Aquí Chatterjee se detiene en la estructura de la excepción de la norma al proveer las bases para llevar el promedio empírico más cerca del deseable normativo mediante un rodeo: se trata una ilegalidad o paralegalidad asociada con una población específica a la manera de una excepción que, no obstante, no perturba el dominio fundamental de la ley. En palabras del autor: "Las decisiones gubernamentales centradas en regular las vastas poblaciones de los pobres urbanos usualmente suman una amplia cantidad de excepciones a la normal aplicación de la ley"16 (2011, pp. 14-15).

Las poblaciones responden a este régimen de gubernamentalidad al constituirse en grupos que merecen la atención del gobierno, con lo que fuerzan la negociación e invitan a las autoridades a declarar una excepción en favor de sus intereses particulares. Cabe señalar que dicha proliferación de excepciones transcurre bajo la mirada recelosa de aquellos que apelan a las normas de la sociedad civil como el exclusivo terreno de la igualdad ciudadana, en oposición a una concepción de igualdad en clave de acceso al bienestar social, a recursos, a la ciudad misma, bajo la que se embanderan las poblaciones ${ }^{17}$. Las excepciones pierden así

$16 \quad$ Traducción del original que versa: "Governmental decisions aimed at regulating vast populations of the urban poor usually add up a huge pile of exceptions to the normal application of the law".

17 Chatterjee (2011) sostiene una paradoja en torno a la común adscripción al discurso de la igualdad entre los sujetos de la sociedad civil y la sociedad 
el estatuto de exclusión de una generalidad para tornarse cada vez más mayoritarias con respecto a su asiduidad $y$ a la población comprendida.

La lectura poscolonial problematiza la existencia de un reconocimiento de derechos formalmente instituidos en situaciones de informalidad, donde las excepciones superan las normatividades; esto es, donde los derechos universales son sustituidos por demandas concretas y particulares. En palabras de Gago (2014): "La sociedad política exhibe la ineficacia de la medicación política moderna cuando la figura de los ciudadanos no es operativa" (p. 285). Sin embargo, las geografías de la sociedad política no se definen por el desierto de derechos en tanto una productividad legal — claro está, de derechos posibles y no de rights - emerge en las prácticas de los sectores populares por vías alternativas a las de la sociedad civil, con lo que se reconocen posiciones de hecho.

En diálogo con el caso de estudio, esta productividad legal permite aproximarse a la CTEP en su construcción de una demanda por derechos (Fernández, 2016). Esta organización parte de la realidad de un extenso conjunto de trabajadores sin derechos, con lo que rompe la ecuación en la cual el trabajo funciona como institución de integración social. Como lo expresa J. Grabois, referente de la organización:

... nuestro desafío se orienta hacia la concreción del reconocimiento de diferentes prácticas laborales a condición de que se reconozca en el plano societal un mínimo de garantías colectivas y jurídicas para el conjunto de los trabajadores, sobre la base de su pertenencia común a sistemas de regulaciones jurídicas garantizadas por el Estados (2017, p.9).

política: las fuerzas de la sociedad política intentan utilizar las instituciones legales para extender el campo de las excepciones desde una base moral que busca asegurar mayor igualdad (igualdad en el acceso al bienestar, a los recursos). A su vez, aquellos que sostienen las normas de la sociedad civil como el espacio de ciudadanía igualitaria, resisten la proliferación de excepciones también al inscribirse en el terreno de la igualdad (ciudadanía como espacio de iguales).
Del fragmento anterior, se infiere la intencionalidad de asimilar los derechos de los trabajadores de la economía popular a los del resto de la clase trabajadora, al cuestionar el trabajo asalariado - y no al trabajo- como única vía de acceso a derechos sociales ${ }^{18}$. $\mathrm{Pa}$ recería sostenerse, traducido en los términos de Chatterjee, que la multiplicación de excepciones hacen del fenómeno exterior la norma y de la modalidad asalariada la excepción, con lo que se disputan las formas de participación y de distribución de la riqueza.

Lo novedoso de la CTEP y que rebasa las consideraciones de Chatterjee, radica en el esfuerzo por otorgar altos grados de formalización y legalización —en clave de derechos legales - a sus derechos adquiridos que, según la lectura poscolonial, nunca alcanzan el rango $y$ las implicaciones de los rights. En este marco, se inscribe la construcción de una demanda por derechos, inexistente previamente a la СTEP, y las acciones de incidencia que dieron lugar a marcos regulatorios específicos para la economía popular: la personería social de la CTEP, la Ley de Emergencia Social y de las Organizaciones de la Economía Popular, y la actual búsqueda por lograr nuevas leyes para el sector ${ }^{19}$.

Si se retoma la idea de la espacialidad de la intersección, estas conquistas demarcan una paradoja. Por una parte, la personería y la ley se tramitaron conforme a los canales institucionales en la construcción de formas alternativas y alterativas de ciudadanización. Por otra parte, la obtención de la personería social (en vez de la buscada personería gremial), las reediciones de planes de lucha en pos de la cabal implementación de la Ley como la limitación temporal de la "emergencia social" al lapso de tres años (presente en el mismo articulado de la Ley), devuelve

18 Es interesante notar que dicha asimilación no implica convertirse en asalariados, sino que se utiliza como base para la lucha por la obtención de derechos colectivos, al partir de la condición de derechos no reconocidos, antes que de carencia de derechos (Fernández, 2016).

19 Las leyes que actualmente reclama la стEP son de Emergencia Alimentaria, Integración Urbana, Infraestructura Social, Emergencia en Adicciones y Agricultura Familiar. 
al plano de la gestión diferenciada basada en acuerdos parciales, heterogéneos y provisionales. Dichos acuerdos están siempre sujetos a nuevos acuerdos y negociaciones, aun cuando el otorgamiento de derechos legalmente sustentados — semejantes a los de los trabajadores formales - se haya articulado con base en la institucionalidad clásica de la sociedad civil.

\section{REFLEXIONES FINALES}

En este artículo se propuso identificar las contribuciones de la lectura poscolonial de Chatterjee a la intelección de la economía popular argentina contemporánea, centrándose en el caso de la стEP como sujeto de la representación colectiva del sector. En la aproximación a la economía popular, se asumió su carácter de espacialidad de la intersección, al cuestionar las perspectivas que la sitúan en la pura exterioridad respecto de la institucionalidad (política, legal, laboral) como de aquellas que la conciben en un simple paralelismo de experiencias sin posibilidades de incidencia concreta en la formalidad. Por lo tanto, la alusión a la intersección permitió dar cuenta de los grises, de las dualidades que no se excluyen y operan en simultáneo, de las imbricaciones $y$ los solapamientos que no invalidan las disyunciones.

Con esta clave teórico-epistemológica, se indagaron tres dimensiones de la economía popular para las cuales se consideró que la lectura poscolonial habilitaba sugerentes claves de análisis. Por un lado, la caracterización del universo de las prácticas cotidianas del heterogéneo mundo de la economía popular supuso recuperar un complejo entramado inscripto en la simultánea exterioridad, paralelismo e interpenetración con la formalidad. Por otro lado, se postuló que la construcción del sujeto trabajador de la economía popular se despliega entre la caracterización de la especificidad del sector dinamizada por la CTEP, ciertos intentos conservadores del movimiento obrero organizado y de los ciudadanos de sujetarlos a la identidad de beneficiarios — negando su identidad laboral—, así como de la apelación de los trabajadores de la economía popular a la ciudadanía y el trabajo, pese a los procesos de expulsión, omisión y exclusión vinculados a dichos conceptos en sus acepciones clásicas.

Finalmente, se señaló que la creación de una demanda por derechos y su traducción en corpus legales emplaza a los actores de la economía popular entre los derechos "posibles", fruto de acuerdos y negociaciones con carácter de excepción con las autoridades estatales, y las posibilidades ciertas de incidir para el logro de derechos formalmente sustentados. Desde la perspectiva retomada, el Estado - aún en su condición de Estado-nación moderno occidental- sigue estando en el centro de la escena como garante de necesidades sociales y como mediador para el reconocimiento y la efectivización de ambos tipos de derechos.

En resumen, la focalización en la política popular urbana y la mirada realista son dos elementos en los cuales se destaca la lectura de Chatterjee y que permiten extrapolar su pensamiento más allá de las latitudes que operan como el estricto contexto de producción de su obra en las sociedades poscoloniales asiáticas. En este sentido, un elemento adicional que se vislumbra en la obra de Chatterjee, reside en situar la politicidad intrínseca a la micropolítica cotidiana donde la gestión de demandas específicas no queda reducida a la obtención de medidas de tipo administrativo ( $y$ tal vez de derechos legales como lo muestra el caso de la CTEP).

Sin lugar a duda, este autor sentencia que los gobernados - las poblaciones de la sociedad política, los sectores populares- hacen política $y$, como consecuencia, pueden cuestionar los términos de la política, el derecho, la estatalidad y la democracia occidental. Si bien, la política de los gobernados se ubica en una posición equidistante tanto de la tradición liberal como del paradigma revolucionario, la disputa al interior de la gubernamentalidad analizada a lo largo de este artículo con relación a la economía popular, es asumida como vocación de una profundización democrática.

\section{REFERENCIAS}

Abal, P. (2016). Los trabajadores y sus organizaciones durante los gobiernos kirchneristas. Nueva Sociedad, (264), 72-86. 
Álvarez, L. (2016). Ciudadanía y acceso a los bienes urbanos en la Ciudad de México. El movimiento urbano popular. En Lucía Álvarez Enríquez (coord.), Ciudadanía y nuevos actores en grandes ciudades. UAM-UNAM-Juan Pablos Editor.

Álvarez, L. (2019). Ciudadanía e informalidad: la crítica poscolonial y la defensa de los derechos adquiridos. (Re)Pensar la Ciudadanía en el siglo XXI. CEIICH-UNAM/ Juan Pablos.

Antunes, R. (2005). Los Sentidos del trabajo. Ensayo sobre la afirmación y la negación del trabajo. Herramienta Ediciones.

Arcidiácono, P. y Bermúdez, A. (2018) $¿$ Cooperativismo como oportunidad perdida? Problemas estructurales y coyunturales del cooperativismo bajo programas. Ciudadanías, 2 (1), 83-111. http:// ciudadanias.untref.edu.ar/pdf/n2_dossier_art4.pdf

Bruno, D., Coelho, R. y Palumbo, M. (2017). Innovación organizacional e institucionalización conflictiva de las organizaciones de la Economía Popular. El caso de la Confederación de Trabajadores de la Economía Popular (CTEP). Argumentos. Revista de Crítica Social, 19, 90-115.

Castronovo, A. (2018). Making the city of commons! Popular economies between urban conflicts and capitalist accumulation: an ethnographic perspective from Argentina. Tracce Urbane, (4), 144-170. https://ojs.uniroma1.it/index.php/TU/ article/view/14366

Chatterjee, P. (2008). La nación en tiempo heterogéneo y otros estudios subalternos. Siglo XXI.

Chatterjee, P. (2011). Lineages of political society. Studies in Postcolonial Democracy. Columbia University Press.

Danani, C., Arias, A., Chiara, M. y Gluz, N. (2018). Instrumentos, estrategias, apoyo $y$ oposición en la contra-reforma de política social. Argentina, 2002-2015. Revista MERCOSUR de políticas sociales, 2, 132-150.

De la Garza, E. (2010). Del concepto ampliado de trabajo al de sujeto laboral ampliado.
Sindicatos y Nuevos movimientos Sociales en América Latina. ClACSO.

De Soto, H. (1987). El Otro Sendero. Instituto Libertad y Democracia.

Fernández, M.I. (2015). Contribuciones antropológicas al estudio de las cooperativas de trabajo en la Argentina reciente. Revista del Centro de Estudios de Sociología del Trabajo, 7, 37-63. http://bibliotecadigital.econ.uba. $\mathrm{ar} / \mathrm{a}=\mathrm{d} \& \mathrm{c}=$ revcesot\&d$=$ revcesot $n$ 7 02

Fernández, M.I. (2016). Experiencias de precariedad, creación de derechos y producción colectiva de bienestar(es) desde la economía popular. Ensambles, 3 (4-5), 72-89. http://www.revistaensambles.com.ar/ojs2.4.1/index.php/ensambles/article/view/76

Gago, V. (2014). La razón neoliberal. Economías barrocas y pragmática popular. Tinta Limón.

Gago, V. (2018). What are popular economies? Some reflections from Argentina. Radical Philosophy, 2 (2), 31-38.

Gago, V. y Stzulwark, D. (2016). The Temporality of Social Struggle at the End of the "Progressive" Cycle in Latin America. The South Atlantic Quarterly, 115 (3), 606-614. https://read.dukeupress.edu/south-atlantic-quarterly/ article-abstract/115/3/606/3850/TheTemporality-of-Social-Struggle-at-theEnd-of?redirectedFrom=fulltext

Giraldo, C. (2017). La economía popular desde abajo. Ediciones desde abajo.

Grabois, J. (2017). Personería Social. Perspectivas en torno al nuevo régimen de agremiación para los trabajadores de la economía popular. Facultad de Derecho de la Universidad de Buenos Aires.

Hopp, M.V. (2017). Transformaciones en las políticas sociales de promoción de la economía social y del trabajo en la economía popular en la argentina actual. Cartografías del sur, (6), 19-41.

Leal, A. (2016) Informalidad y ciudadanía en la Ciudad de México. Ciudadanía y nuevos actores en grandes ciudades. Lucía Álvarez Enríquez (coord.). UAM-UNAMJuan Pablos Editor. 
Lijterman, E. (2018). Políticas de promoción de la economía social en Argentina: una aproximación desde los saberes expertos. Revista Íconos, 62, 22 (3), 65-85. http:// revistas.flacsoandes.edu.ec/iconos/article/view/3254

Mezzadra, S. y Neilson, B. (2016). La frontera como método, o la multiplicación del trabajo. Tinta Limón.

Retamozo, M. y Morris, B. (2015). Sindicalismo y Política. La Central de Trabajadores Argentinos tiempos kirchneristas. Estudios Sociológicos, 33(97), 63-87.
Roy, A. (2009). Why India cannot plan its cities: informality, insurgence and the idiom of urbanization. Planning Theory, 8 (1), 76-87.

Tóffoli, M. (2017). La "CGT de los excluidos". La Confederación de Trabajadores de la Economía Popular (стEP) (2011-2016). [Tesis de Licenciatura en Sociología]. Universidad de La Plata, La Plata, Argentina. http://www.memoria.fahce. unlp.edu.ar/tesis/te.1402/te.1402.pdf

Fecha de ingreso: 07/03/2019 Fecha de aprobación: 28/05/2020 